\title{
Legislation for Teeth Brushing: Don't Brush the Occlusal Surface (Biting Surface) of Molar and Premolar Teeth
}

\author{
Farhad Jahangiri* \\ Department of Veterinary Parasitology, Shiraz University, Iran
}

Received: 粊 February 09, 2018; Published: February 16, 2018

*Corresponding author: Farhad Jahangiri, Department of Veterinary Parasitology, Shiraz University, Iran

\section{Opinion}

Human and animals break food particles by cutting and crushing them amides of upper and lower teeth. It is clear that this mechanical action can partly cause abrasion of the occlusal surface (biting surface) of teeth. In some animals like rabbit, this abrasion is very rapid and intense because of tight food. To compensate for this wear these animals have teeth that grow continuously [1]. Although human meal usually is not so hard; but Human is not an exception of teeth abrasion during chewing food. One obvious evidence for this is absence of dental plaque on the biting surface in people who don't brush their teeth. Although this people don't brush, there is no dental plaque in biting surface of their teeth. They have plaque just in surfaces far from the biting area. Anyway, this abrasion by food is so slight that cannot easily cause wear of enamel of teeth; but additional abrasive agents can cause serious damage to the enamel. One of these additional abrasive agents can be the toothbrush especially in obsessive persons. Teeth brushing are a difficult and overwhelming action for children. For this reason, they usually tend to brush the easily accessible surfaces of teeth (occlusal surface); But this unconscious action can not damage the enamel of teeth in children. Because children end brushing very soon.

Since they don't like teeth brushing and they also don't have enough strength for continuous and intense brushing. Conversely, teenagers that try to be more adorned and clean make brushing longer and more severe. They may also use a hard toothbrush and more effective toothpaste. While it's still easy to brush the biting surface of the teeth. Finally, frequent sever rubbing by toothbrush accompanied by food rubbing leads to the abrasion of enamel and dentin of molar and premolar teeth. Many studies have provided the cariogenic effects of toothpaste and toothbrush on teeth [2-4] and other studies have presented evidences of the food type effect of teeth wear [5-7]; But they never sum the rubbing resulted from brushing and chewing and they never presented a definitive rule based on the available Information. In this article we are going to openly announce that disadvantages of brushing the biting surface of teeth are very more than its advantages. We are going to define a rule as "Do not brush the biting surface of teeth". Brushing training should emphasize the avoidance of brushing biting surfaces of teeth. Brushing on the biting surfaces should make just to remove the particles stuck in dentine of teeth and not more.

Overall, our reasons for prohibition of brushing the biting surfaces of teeth are as follows:

i. Food even in soft type can cause mechanical abrasion of enamel and dentine of teeth $[1,5]$.

ii. Unlike some animals, human teeth don't have permanent growth [1]. For this reason, the erosion factors should be minimized.

iii. Food chewing alone prevents plaque formation and makes the biting surface shiny wear of enamel and dentine can be dramatically increased if tooth brushing follows an erosive challenge [2].

\section{References}

1. Capello V, Gracis M, Lennox AM (2005) Rabbit and rodent dentistry handbook. Zoological education network.

2. Addy M, Hunter ML (2003) Can tooth brushing damage your health? Effects on oral and dental tissues. International Dental Journal 53(S3): 177-186.

3. Addy M (2005) Tooth brushing, tooth wear and dentine hypersensitivityare they associated?. International Dental Journal 55(S4): 261-267.

4. Hunter ML, Addy M, Pickles MJ, Joiner A (2002) The role of toothpastes and toothbrushes in the aetiology of tooth wear. International dental journal 52(S5): 399-405.

5. Stephan RM (1966) Effects of different types of human foods on dental health in experimental animals. Journal of Dental Research 45(5): 15511561. 
6. Duggal MS, Toumba KJ, Amaechi BT, Kowash MB, Higham SM (2001) Enamel demineralization in situ with various frequencies of carbohydrate consumption with and without fluoride toothpaste. Journal of Dental Research 80(8): 1721-1724.
7. Krasse B (2001) The Vipeholm Dental Caries Study: recollections and reflections 50 years later. Journal of Dental Research 80(9): 1785-1788.
(C) (P) This work is licensed under Creative

To Submit Your Article Click Here: Submit Article

DOI: 10.32474/MADOHC.2018.01.000111

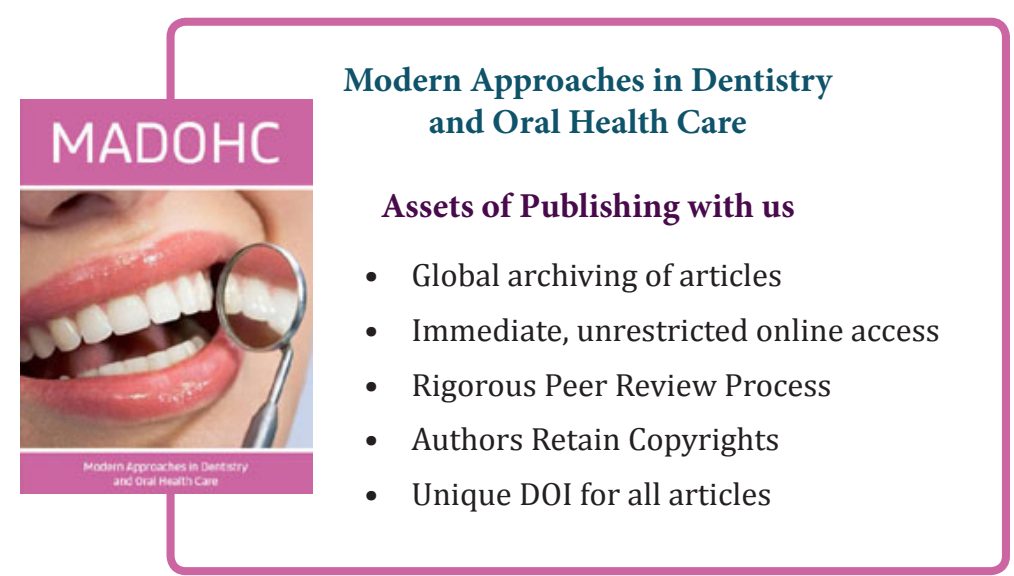

